\title{
PROBABILITY MODELS FOR THE DISTRIBUTION OF COPEPODS IN DIFFERENT COASTAL ECOSYSTEMS ALONG THE STRAITS OF MALACCA
}

\author{
HAZEL MONICA MATIAS-PERALTA \\ Institute of Bioscience, Universiti Putra Malaysia, \\ Serdang, Selangor 43400 UPM, Malaysia \\ hmp1229@yahoo.com \\ ALIREZA GHODSI \\ Department of Mathematics, \\ Faculty of Science, Universiti Putra Malaysia \\ Serdang, Selangor 43400 UPM, Malaysia \\ and \\ Department of Mathematics, Faculty of Science, \\ Tarbiat Moallem University of Sabzevar, \\ Sabzevar, Khorasan 9617976487, Iran \\ ghodsiir@gmail.com \\ MAHENDRAN SHITAN \\ Laboratory of Computational Statistics and Operations Research, \\ Institute for Mathematical Research, Universiti Putra Malaysia \\ and \\ Department of Mathematics, Faculty of Science, Universiti Putra Malaysia, \\ Serdang, Selangor 43400 UPM, Malaysia \\ sarasmahen@gmail.com \\ FATIMAH MD. YUSOFF \\ Institute of Bioscience, Universiti Putra Malaysia \\ and \\ Department of Biology, Faculty of Science, Universiti Putra Malaysia, \\ Serdang, Selangor 43400 UPM, Malaysia \\ fatimah@ibs.upm.edu.my
}

\begin{abstract}
Copepods are the most abundant microcrustaceans in the marine waters and are the major food resource for many commercial fish species. In addition, changes in the distribution and population composition of copepods may also serve as an indicator of global climate changes. Therefore, it is important to model the copepod distribution in different ecosystems. Copepod samples were collected from three different ecosystems (seagrass area, cage aquaculture area and coastal waters off shrimp aquaculture farm) along the coastal waters of the Malacca Straits over a one year period. In this study the major sta-
\end{abstract}




\begin{abstract}
tistical analysis consisted of fitting different probability models. This paper highlights the fitting of probability distributions and discusses the adequateness of the fitted models. The usefulness of these fitted models would enable one to make probability statements about the distribution of copepods in three different ecosystems.
\end{abstract}

Keywords: Probability models; Copepods; Coastal ecosystems.

Mathematics subject classification: $62 \mathrm{P} 10$

\title{
1. Introduction
}

Copepods are considered to be the most important metazoan secondary producers in marine ecosystems both in terms of abundance and biomass. They play a vital role serving as a link between phytoplankton and higher trophic levels. Studies of zooplankton in coastal and even oceanic waters of the world have shown that copepods constitute the most important group in marine zooplankton communities. Copepods dominate the zooplankton of most tropical waters including Malaysia. In fact, studies in the coastal and neritic waters along the Straits of Malacca show that copepods accounted for more than $60 \%$ of the zooplankton collected. ${ }^{1}$ Copepods have ubiquitous distribution and high relative abundance; therefore, they constitute the most important group in marine zooplankton communities.

In describing the distribution and estimating the abundance of copepods in the marine ecosystems, it has become increasingly evident that individuals are seldom, if ever, randomly distributed in space. Most commonly, the distribution of sample counts' variance is in excess of random expectation (i.e. greater than their mean) or the distribution of samples are not normal. In fact, most biological communities tend to aggregate in the seas due to their natural behaviour. In such cases, it may be regarded that the precision of the estimate is correspondingly reduced. However, if the data set is not normally distributed or there is excess variance, these may imply that the distribution of individuals has a partially determined pattern, and thus may be regarded as a reservoir of information about the behaviour of the organisms concerned. Suitable mathematical models, which describe this pattern, may be an aid to the extraction of many important information.

Therefore, in this study, different probability models were fitted to the data set to find the most suitable fit, which in turn may enable one to make probability statements about the distribution of copepods in different ecosystems.

\section{Materials and Methods}

\subsection{Location of the study}

Three different habitats in three different locations along the coastal zone of the Straits of Malacca were selected (Fig. 1); these are the coastal waters off a shrimp aquaculture farm $(\mathrm{SF})$, sea grass beds/meadow $(\mathrm{SG})$ and cage mariculture area (CA). 


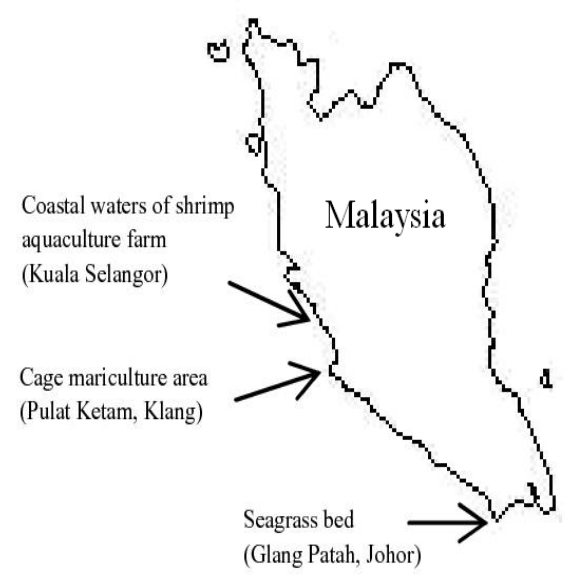

Fig. 1. Map of the Straits of Malacca. Arrows indicate the sampling locations along the coastal zones of the Straits.

\subsubsection{Coastal waters of shrimp aquaculture farm}

Kuala Selangor is a fishing village located in Sungai Selangor estuary and is also popularly known for the firefly habitat, associated with mangrove species, Sonneratia caseoloris. Kuala Selangor estuary is the end point of several rivers that received both the domestic and industrial waste discharges before entering the Malacca Strait. The sampling stations were located $1 \mathrm{~km}$ away from the thinned mangrove forest which can barely hide the shrimp aquaculture farm from the view.

\subsubsection{Seagrass bed/meadow}

The seagrass meadow popularly known as Merambong shoal is approximately 40-ha oval shaped meadow (it stretches almost $2 \mathrm{~km}$ long at the largest patch) located between the Causeway second link and the Pulau Merambong, Southwest of Johore in Peninsular Malaysia and is the most extensive seagrass covered subtidal shoal in Malaysian waters. ${ }^{2}$ The seagrass bed is vegetated by seagrass species which were mainly Enahulus acroides, Halopila spp. and Syringodium spp among others. Around the area nearby the seagrass meadow is slated for heavy industry (a large port, chemical processing plants, oil and gas refineries and storage and a powerplant).

\subsubsection{Cage mariculture area}

Pulau Ketam cage mariculture area is located along the coastal waters of the Straits of Malacca, which is 12 nautical miles away from the Port Klang (one of the major Malaysian industrial ports). Floating cages are set up in calm water, which is situated behind an island (Pulau Ketam) near a river mouth. The water depth is at average $8 \mathrm{~m}$ during the highest high tide and $5-6 \mathrm{~m}$ during low tide. The 
site is relatively free from domestic, industrial and agricultural wastes and other environmental hazards.

\subsection{Copepod sample collection}

Samples were collected using conical shaped (with mouth opening size of $0.30 \mathrm{~m}$ and $1.00 \mathrm{~m}$ length) plankton net with 100 mesh with an acrylic plastic cod end. Triplicate samples from four randomly selected stations from different ecosystems were collected. Samples were carefully transferred in labeled sample bottles and immediately preserved with $5 \%$ buffered ( $\mathrm{pH} 8.0-8.2$ ) formalin. ${ }^{3}$

\subsection{Copepod density estimation}

Samples were filtered in a $350 \mathrm{~m}$ mesh size net filter to separate the bigger organisms (in this case the entire copepod portion passed through the net due to their smaller size). Then the remaining portion was sorted out under dissecting microscope (Nikon model SMZ645) to separate the copepod from non-copepod portions. For the highly concentrated samples, dilution was performed before sub sampling was done. The samples were first poured in the $500 \mathrm{ml}$ graduated cylinder and diluted with filtered sea water to 200-500 ml volume depending on how concentrated the sample was. Using a Stempel pipette, $10 \mathrm{ml}$ of the sample was drawn and transferred into a Bogorov counting chamber and counted under the Nikon dissecting microscope (Nikon model SMZ645). The copepod density was calculated according to the formula: ${ }^{4}$

$$
N=\frac{n S}{w}
$$

where $N$ is the number of individuals per cubic meter of water filtered, $n$ is the number of individuals in the subsample $(10 \mathrm{ml}), S$ is the fraction number of the subsample $(250 / 10)$ and $w$ is the volume of water filtered. Note that volume of water filtered was calculated following Ref. 5 as,

$$
\text { Volume of water filtered }(w)=A s
$$

where $A$ is the mouth area of the net and $s$ is the depth of tow.

\subsection{Statistical analysis}

The main statistical analysis done in this study is to fit probability models to the copepods data observed at the above-mentioned ecosystems. We fitted several types of distributions to the data set and then compared how well they fit the data. Three probability distributions namely, Normal, Gamma and Log-normal, were considered in this study. The probability densities of these distributions are respectively listed below,

$$
f(y)=\frac{1}{\sqrt{2 \pi} \sigma} e^{-\frac{(y-\mu)^{2}}{2 \sigma^{2}}}, \quad y \in \mathbb{R}, \mu \in \mathbb{R}, \sigma^{2}>0
$$




$$
\begin{array}{cl}
f(y)=\frac{1}{\Gamma(\alpha) \beta^{\alpha}} y^{\alpha-1} e^{-\frac{y}{\beta}}, & y>0, \alpha>0, \beta>0 \\
f(y)=\frac{1}{y \sqrt{2 \pi} \sigma} e^{-\frac{(\ln y-\mu)^{2}}{2 \sigma^{2}}}, & y>0, \mu \in \mathbb{R}, \sigma^{2}>0
\end{array}
$$

Since the values of the original data $\left\{x_{1}, x_{2}, \cdots, x_{n}\right\}$, were very large, they were transformed to $y_{i}=x_{i} / c,\{i=1, \cdots, n\}$, where $c=300,000$ (for SF) and 20,000 (for $\mathrm{SG}$ and $\mathrm{CA}$ ). This transformation was done in order to avoid numerical difficulties.

To the transformed data $\left\{y_{i}\right\}$, we fitted the Normal, Gamma and Log-normal distributions. Since $y_{i}=x_{i} / c$, we have $x_{i}=c y_{i}$. Using the moment generating function, it can be shown that if $Y_{i} \sim \operatorname{Normal}\left(\mu, \sigma^{2}\right)$, then $X_{i} \sim \operatorname{Normal}\left(c \mu, c^{2} \sigma^{2}\right)$. Similarly, it can be shown that if $Y_{i} \sim \operatorname{Gamma}(\alpha, \beta)$, then $X_{i} \sim \operatorname{Gamma}(\alpha, c \beta)$. However, the moment generating function does not exist for the Log-normal random variable but by using the characteristic function, we can still show that if $Y_{i} \sim \log$ $\operatorname{Normal}\left(\mu, \sigma^{2}\right)$, then $X_{i}$ is also $\log -\operatorname{Normal}\left(\mu+\ln c, \sigma^{2}\right)$.

Finally the adequateness of the models were accessed by Q-Q plots, goodness-offit tests (Chi-square test and Kolmogrov-Smironov test) and $A I C$ statistic. ${ }^{6}$ A somewhat straight Q-Q plot indicates a good fit. The null hypothesis of the goodness-offit test is that the data is consistent with the hypothesized distribution. The higher the $p$-value of these tests, the closer the fitted distribution appears to match the data. The $A I C$ statistic is defined as,

$$
A I C=2 k-2 \ln L
$$

where $k$ is the number of parameters in the statistical model, and $L$ is the maximized value of the likelihood function for the estimated model. Given a set of candidate models for the data, the preferred model is the one with the minimum $A I C$ value.

The entire statistical analysis was done using the $R$ statistical package.

\section{Results and Discussion}

In this section the results are discussed. In subsection 3.1 the results for coastal waters of shrimp aquaculture farm are discussed. In subsections 3.2 and 3.3 the results for sea grass bed and cage mariculture area are presented, respectively.

\subsection{Coastal waters of shrimp aquaculture farm}

In Table 1 the results for the fitted distributions are shown. Using Chi-square test, it shows that the Normal distribution is not suitable to the data because of the very small p-value of 0.00000635 (Table 1). Similarly, the Kolmogrov-Smironov test also rejects the null hypothesis that the data is Normal at $0.05 \alpha$-level. On the other hand, the $p$-value of both the Chi-square and Kolmogrov-Smironov tests for the Log-normal distribution is larger than the Gamma distribution. In addition, the AIC statistics for the Log-normal distribution is less than the Gamma distribution, 
Table 1. Goodness-of-fit tests for the fitted distributions to the transformed SF data.

\begin{tabular}{lccc}
\hline & & \multicolumn{2}{c}{ Goodness-of-fit test (p-value) } \\
\cline { 3 - 4 } Fitted distribution & AIC & Chi-square & Kolmogrov-Smironov \\
\hline Normal $(5.367,12.797)$ & 391.870 & 0.00000635 & 0.02975 \\
Gamma $(2.408,2.229)$ & 364.946 & 0.064 & 0.3172 \\
Log-normal $(1.458,0.469)$ & 363.894 & 0.257 & 0.6641 \\
\hline
\end{tabular}
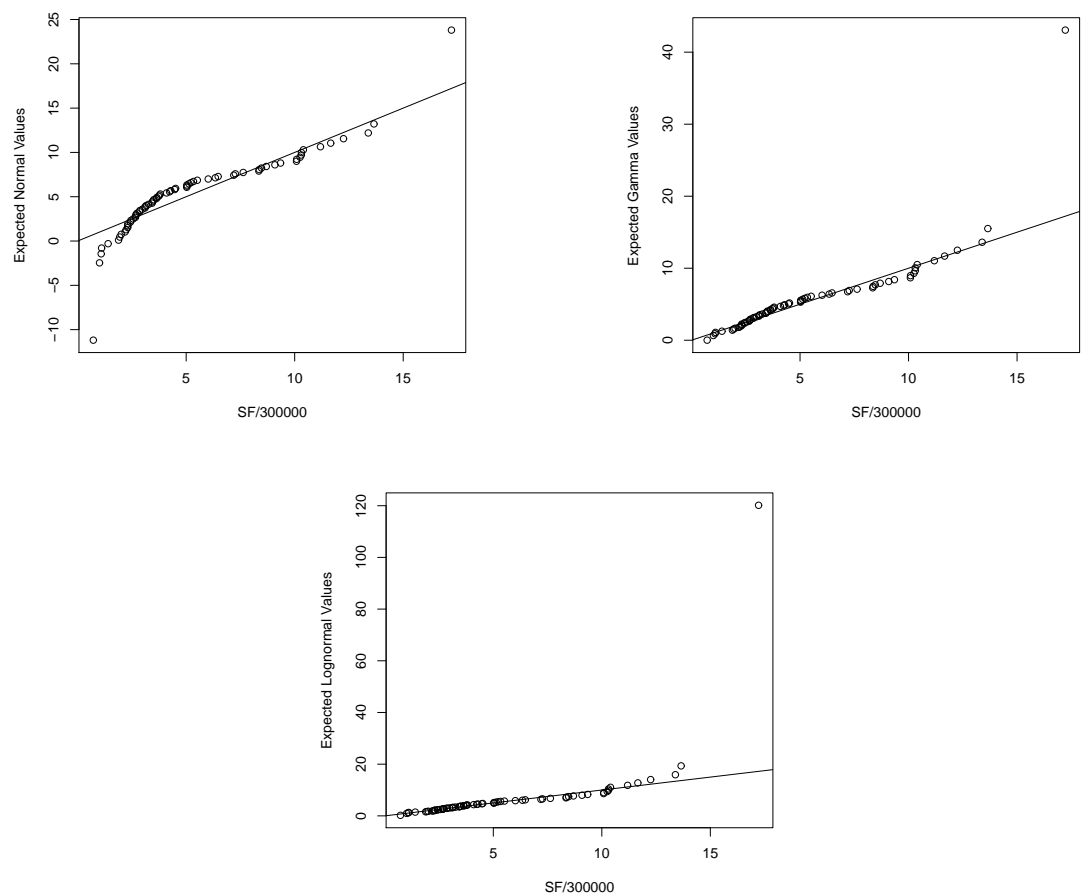

Fig. 2. Q-Q plots of the Fitted distributions to the transformed SF data.

suggesting a better fit than the Normal and Gamma distribution to the copepod data.

From the Q-Q plot it is also evident (Fig. 2) that the Log-normal is also the better fit in comparison with Normal and Gamma distributions. Figure 3 shows the histogram of the copepod data which is over-layered by the fitted probability curves. Based on these evidence, it appears that the Log-normal is a reasonable fit.

\subsection{Seagrass bed/meadow}

From Table 2 we can see that the Normal and Gamma distributions are not suitable to the copepod data. It clearly rejects the null hypothesis at 0.05 level for 


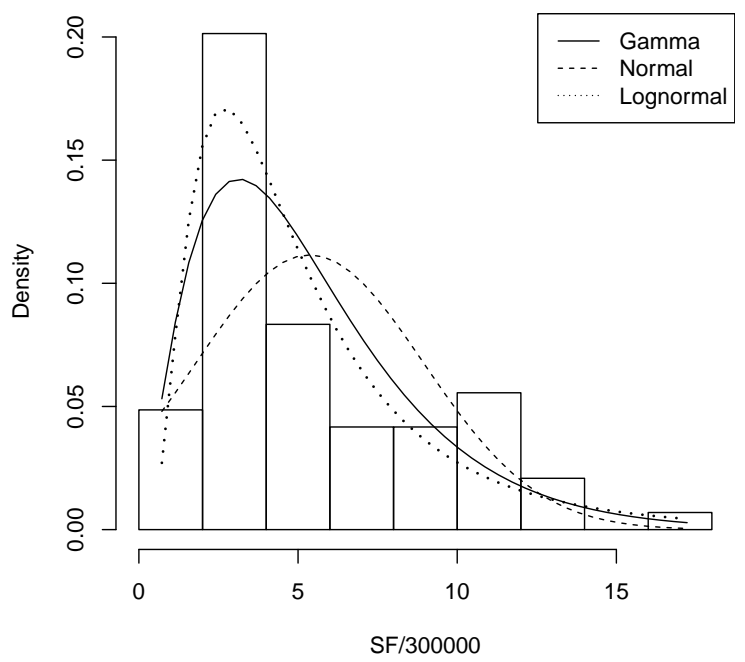

Fig. 3. The fitted probability curves to the transformed SF data.

Table 2. Goodness-of-fitted distribution to the transformed SG data.

\begin{tabular}{lccc}
\hline & & \multicolumn{2}{c}{ Goodness-of-fit test (p-value) } \\
\cline { 3 - 4 } Fitted distribution & AIC & Chi-square & Kolmogrov-Smironov \\
\hline Normal $(10.789,186.068)$ & 584.607 & $2.838 \mathrm{e}-44$ & $1.161 \mathrm{e}-05$ \\
Gamma $(0.713,1.402)$ & 484.299 & $1.226175 \mathrm{e}-06$ & $8.882 \mathrm{e}-16$ \\
Log-normal $(1.533,1.800)$ & 471.446 & 0.003 & 0.227 \\
\hline
\end{tabular}

both Chi-square and Kolmogrov-Smironov tests. Note that the $A I C$ statistics for the Log-normal has the lowest value among the three distributions. Moreover, the $p$-value of the Kolmogrov-Smironov test is greater than 0.05, suggesting that Log-normal distribution is the reasonable fit for the copepod data amongst the three distributions. It is also evident from the Q-Q plot (Fig. 4) that the Log-normal is the better fit in comparison with both the Normal and Gamma distributions. Figure 5 shows the histogram of the copepod data which is over-layered by the fitted probability curves.

\subsection{Cage mariculture area}

In Table 3 the results for the fitted distribution are shown. The null hypothesis for the goodness-of-fit tests are not rejected for all the three distributions. However, among the three distributions considered in this study, the Chi-square and Kolmogrov-Smironov test shows higher $p$-values for the Log-normal distribution which may suggest a better fit. Similarly, the Q-Q plot (Fig. 6) also shows that the Log-normal has the better fit. On the other hand, the $A I C$ statistics for the 

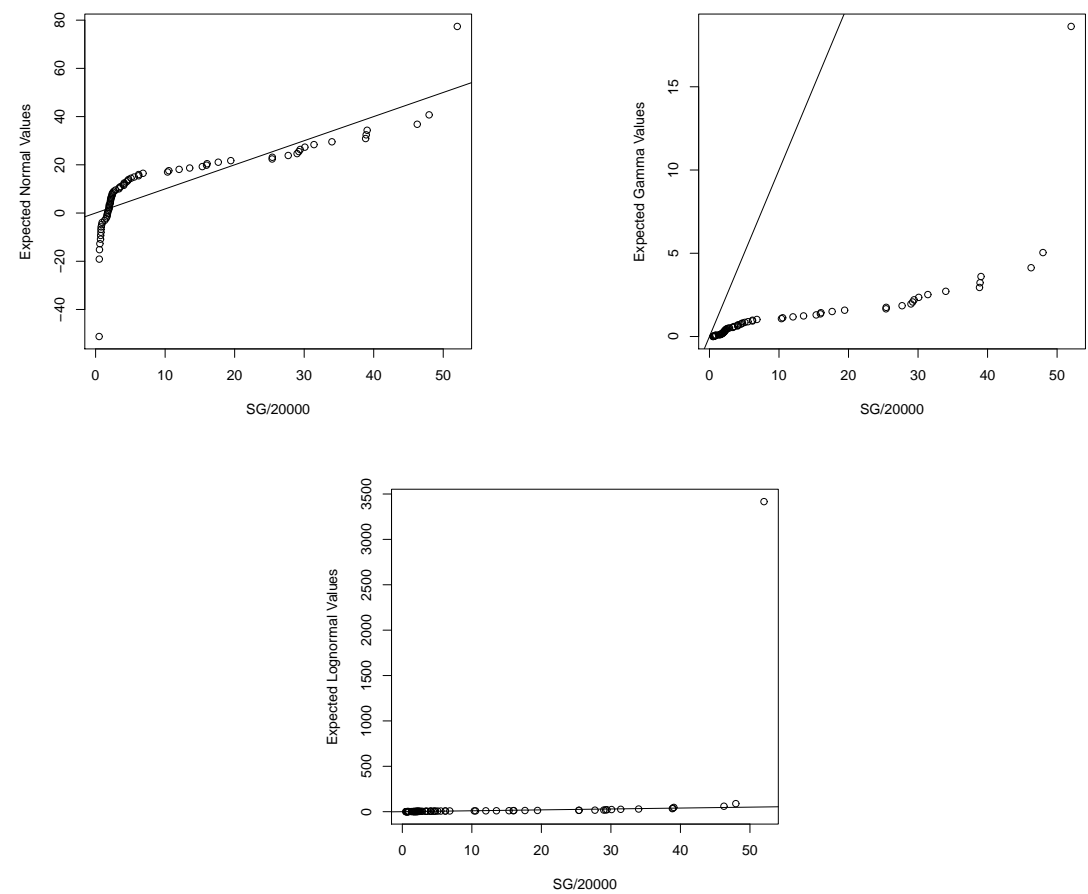

Fig. 4. Q-Q plots of the Fitted distributions to the transformed SG data.

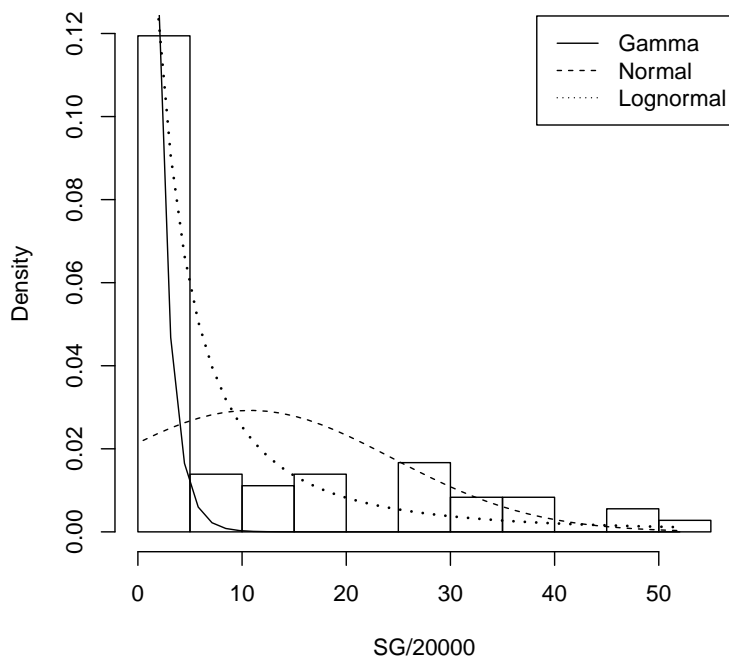

Fig. 5. The fitted probability curves to the transformed SG data. 
Table 3. Goodness-of-fitted distribution to the transformed CA data.

\begin{tabular}{lccc}
\hline & & \multicolumn{2}{c}{ Goodness-of-fit test (p-value) } \\
\cline { 3 - 4 } Fitted distribution & AIC & Chi-square & Kolmogrov-Smironov \\
Normal $(1.689,0.267)$ & 113.319 & 0.256 & 0.1482 \\
Gamma $(10.519,0.161)$ & 109.691 & 0.599 & 0.5522 \\
Log-normal $(0.476,0.101)$ & 111.517 & 0.665 & 0.6046 \\
\hline
\end{tabular}
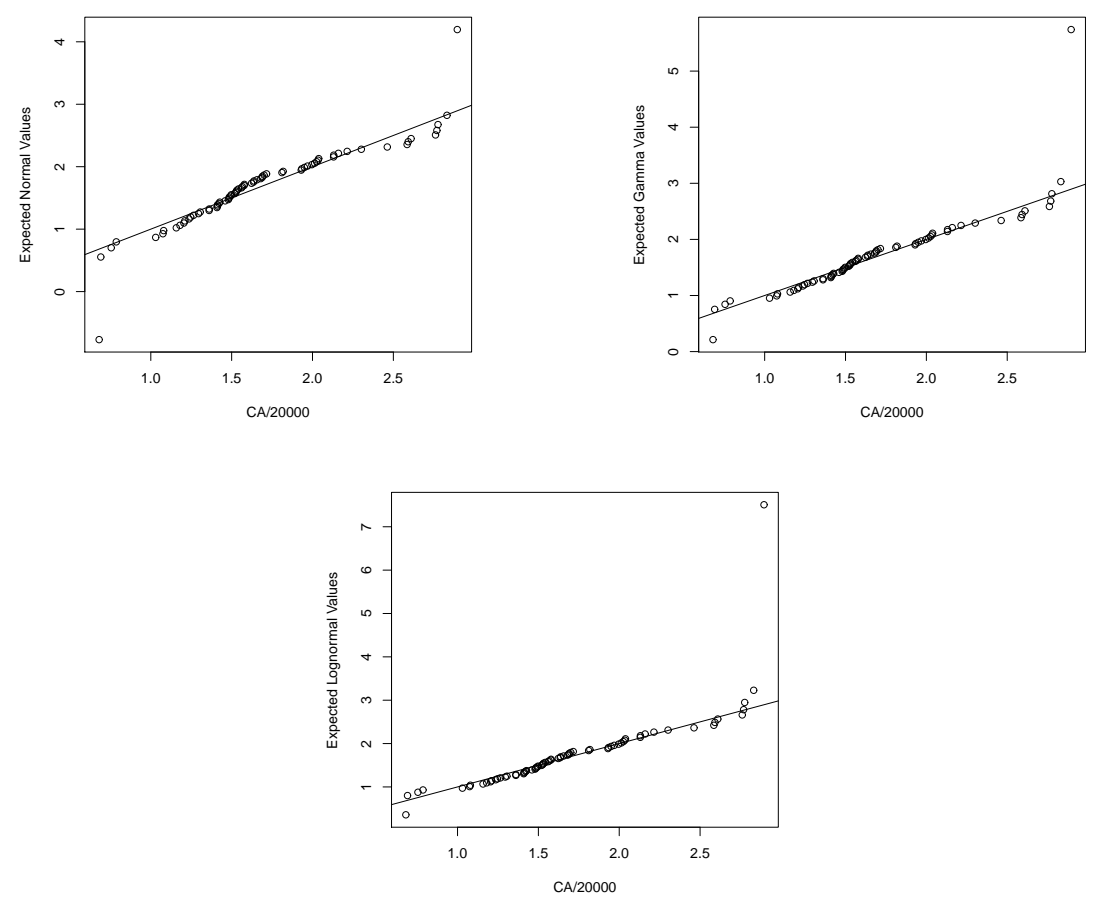

Fig. 6. Q-Q plots of the Fitted distributions to the transformed CA data.

Gamma distribution has the lowest value among the three distributions. Therefore in this case, it is rather difficult to make a choice between the Gamma and Lognormal distributions. Figure 7 shows the histogram of the copepod data which is over-layered by the fitted probability curves.

\section{Conclusion}

The objective of this study was to fit probability distributions to copepods observed in three different ecosystems in coastal waters of the Straits of Malacca. It is quite clear in this study that the Log-normal distribution is the better fit (compared with Gamma or Normal distribution) for the two ecosystems, namely coastal waters of 


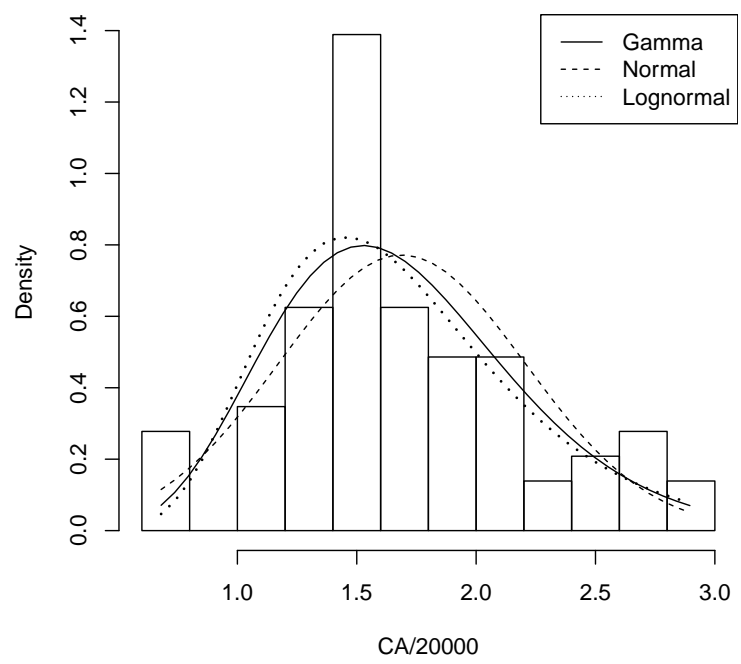

Fig. 7. The fitted probability curves to the transformed CA data.

shrimp aquaculture farm and seagrass bed/meadow. However, for the cage mariculture area it is quite difficult to make a choice between Log-normal and Gamma distribution since both were somewhat close to each other. This is an initial study where we have only considered three distributions. The authors plan to investigate a wider range of distributions which will be reported in a future paper.

\section{Acknowledgments}

This research is supported with the e-Science fund (Project No. 04-01-04-SF0418) and IOC-TEMA Research Grant No: 4500025145.

\section{References}

1. H. M. Rezai, PhD thesis, Universiti Putra Malaysia, Selangor, Malaysia, pp. 265 (2002).

2. S. B. Japar, Z. M. Mutaharah and A. Arshad, Aquatic Ecosystem Health Management, 9, 203-214 (2006).

3. H. F. Steedman (Ed), Zooplankton fixation and preservation, (UNESCO Press, Paris, 1976), pp. 350.

4. UNESCO. Reports and studies No. 32. Land/sea boundary flux contaminants: contribution from rivers. (IMO/FAO/UNESCO/WHO/WMO/UN/UNEP Joint group of experts on the scientific aspects of marine pollution, 1987).

5. G. E. Newell and R. C. Newell, Marine Plankton: a practical guide, (Hutchinson and Co. Ltd. London, 1977), pp. 244.

6. H. Akaike, IEEE Transactions on Automatic Control, AC-19(6), 716-723 (1974). 